\title{
THE SHORT-TERM AND LONG-TERM TRADE-OFF BETWEEN RISK AND RETURN: CHAOS VS RATIONALITY
}

\author{
Chang $\mathrm{LIU}^{1}$, Haoming $\mathrm{SHI}^{1}$, Liang $\mathrm{WU}^{2 *}, \mathrm{Min} \mathrm{GUO}^{3}$ \\ ${ }^{1}$ Southwestern University of Finance and Economics, Chengdu, China \\ ${ }^{2}$ Sichuan University, Chengdu, China \\ ${ }^{3}$ China Great-Wall Asset Management Co., Ltd, Chengdu, China
}

Received 09 December 2018; accepted 01 August 2019

\begin{abstract}
This paper applies the composite construction method proposed by Haugen (1999) and its application by Zhao and Wang (2010) for the Chinese stock market. Utilizing the Shanghai A-share market stocks data, this paper first selects the studying samples from January 1, 1997 to December 31, 2017. A portfolio is then built according to the mean variance model of portfolio structure, and simulation results are analysed using the Wilcoxon Signed Rank Test. The relationship between risk and return in the long and short term is explored. Results indicate no significant relationship between the risk and return of the stock portfolio in the short run, which reflects the short-term ambiguity of the Chinese stock market. However, in the long run, the risk and return of the stock portfolios are positively correlated, which means that high returns are accompanied by high risks, indicating that the stock market will eventually return to rationality. In other words, the A-share stock market will eventually return to be value-driven and the short-term speculators would be outweighed by long-term value investors.
\end{abstract}

Keywords: risk-return relationship, value investors, speculators, long-term rationality, short-term chaos, risk, returns.

JEL Classification: G11, G19, M21.

\section{Introduction}

Modern investment theory claims that high return is accompanied by high risk and low return by low risk. Based on Markowitz's mean-variance model, Sharp, Litner and Mosin derived the Capital Asset Pricing Model (CAPM). The establishment of this model needs to meet a series of strict assumptions including the risk aversion of investors.

Established in the early 90s, China's capital market has a short history of no more than 30 years (Wei, 2001; Shen, 2006). It is still in its infancy compared to markets such as Wall Street and London. In such an emerging market it is difficult to avoid the prevalence of specula-

${ }^{\star}$ Corresponding author. E-mail: LiangWu@scu.edu.cn 
tion (Figure 2 shows the volatility of Shanghai Stock Exchange and US Dow Jones Index). If speculative investors are risk-seeking, the assumption of risk aversion is not reasonable (Wei, 2009). It is believed that the market is composed of investors with different trading styles. Based on this belief, Barberis et al. (2015) constructed a heterogeneous-agent model in which some investors form beliefs about future stock market price changes by inferring past price changes, while others have completely rational beliefs. According to Christensen, Nielsen, and Zhu (2010), in the short term, because the stock market speculation is dominant, "volatility feedback effect" explains the inverse relationship between risk and return. By contrast, when rational investments of long-term investors overwhelm market speculations, the "risk return trade-off" effect makes the simple law of "high risk with high return, low risk with low return" a reality. Understanding the risk preference of the majority participants in a market is important for investors to make investment decision. For instance, investors can choose to keep long-term holdings to obtain higher yields but are not advised to pursue high-risk yet short-term stocks if they believe in high risks with high returns.

This paper contributes to the literature in three aspects. Firstly, this paper studies the transition of Chinese stock investors (especially retail investors) between the two different styles of rationality and speculation by studying the trade-offs of risk and return in both the longand short terms. The second contribution is the usage of the unique samples. In this study, 292 stocks listed in the initial stage of the establishment of China's stock market are selected. Since these stocks have been listed for a long time, investors have a very deep understanding about these stocks, which is favorable for this research. To the best of our knowledge, no other studies have used this sample. Thirdly, we have documented that, China's market risk and return are uncertain in the short term; in the long term, however, the stock market will return to rationality, and long-term value investment can replace short-term speculation. The result is of importance for investors, policymakers, and regulators. For individual investors and buy-side institutional investors, fluctuations could not prevail and the stock market will return to rationality in the long run. Value investment is still an important method for their investment strategies. For sell-side institutional investor, it is not how high their return rates are to make their product promising in the long run: it is the balanced risks and returns that make the portfolio popular. For policymakers, it is important to keep the stock market in a standardized and transparent manner. Furthermore, it helps the market become mature by dictating the participants what should be done instead of what should be prohibited. The benefits to regulators have three folds. First, it enables investors to make a rational choice between long-term and short-term risks and returns, thus making the market and the formulation of regulatory policies more mature. Second, through the analysis of short-term and long-term returns, regulators have a clearer understanding of investors' trading behaviors, thus formulating better targeting policies. Finally, because the maturity cycle of a market is relatively long, regulators can dynamically evaluate the state of the market using the approach proposed in this paper, so as to formulate policies more in line with the actual situation of the market.

The remainder of the paper is organized as follows. Section 2 introduces the model and the methodology. Section 3 presents the data and the empirical results of the study, while the final section concludes. 


\section{Literature review}

Fama and French (1992) found that the $\beta$ did not explain the difference in the returns of different stocks, while size, leverage, book-to-market equity, and earnings-price ratios could explain the difference in stock returns. Hou and Loh (2016) argued that existing literature provided explanations that could only explain less than $10 \%$ of the idiosyncratic volatility. Zaremba (2016) also studied the parallels between the country-level and the stock-level low-risk anomalies and found that country-level returns were positively related to standard deviation, value at risk, and idiosyncratic volatility. Saengchote (2017) confirmed that the abnormal returns associated with investment in low-beta stocks were significant and robust in Thai stock market. Fan and Du (2017) empirically examined the mean spillover and the volatility spillover between the CSI 500 stock index futures market and the underlying spot market. Hong, Ramchander, Wang, and Yang (2017) examined the intraday price discovery and volatility spill-over relationship between the CSI 300 equity index and index futures in China. There were also some documents explaining the relationship between risks and benefits in the long and short term. Cox and Peterson (1994) found that in the long term, beginning from four days after the drop, securities tended to enter a prolonged period of relatively poor performance where the post-drop recovery was itself reversed. These findings were not suggestive of short-term overreaction yielding profitable trading strategies. Furthermore, the lack of a negative correlation between abnormal returns of the following three days was inconsistent with the overreaction theory. Ghysels, Santa-Clara, and Valkanov (2005) used the mixed data sampling approach and found a significantly positive relation between risk and return in the stock market. Lundblad (2007) considered a model with irrational investors who were rational on average, and obtained waves of pessimism and optimism that led to countercyclical market prices of risk and procyclical risk-free rates, discovering that the long run risk-return relation was modified. Jouini and Napp (2011) documented a significantly positive risk return relation by using information from a longer historical record of the U.S. and U.K. equity market experience. (A market capitalization comparison among China, US and UK stock markets is shown in Table 4).

In 1992, China's capital market was set up. As in international financial markets, risk and return had been the basic problem of the China financial market. Zhang, and Ma (2000) pointed out that the relationship between risk and return was not significant. Li (2000) found that the risk return relationship was not a linear relationship as the Shanghai stock market was a very speculative emerging stock market. Wu, Zhao, and $\mathrm{Wu}$ (2002), through empirical analysis, found that high risk with high income and low risk with low income relations only existed in the long term. Chan, Wang, and Wei (2004) concluded that over the long run, stock price performance was not purely driven by speculation, but that it was a reflection of a firm's operating performance. Froot, Scharfstein, and Stein (1992) found that short trading horizons could lead to inefficiencies. Li and Wu (2003), and Guo and Ling (2004) also found that the relationship between risk and return was not linear. Systematic risk could not explain the stock market while idiosyncratic risk played an important role in stock pricing. Yadav, Han, and Rho (2016) analyzed the impact of the environmental performance of firms on their performance in the stock market and observed that firms with better environmental performance had higher standardized cumulative abnormal returns. Benlagha and Chargui (2017) 
measured and compared French stock and bond market volatilities using various range-based volatility estimators and conditional heteroscedasticity models. They found that the bond and stock market volatility behaviors exhibited by the French markets were different from those in major developed asset markets and that the conditional volatilities of nominal bonds had equivalent specifications to those used to model stock volatilities. Lins, Servaes, and Tamayo (2017) found that firms with high corporate social responsibility (CSR) ratings outperform those with low CSR ratings during the crisis by at least four percentage points. After controlling for a variety of firm characteristics and risk factors, they also found that the excess returns were higher for firms headquartered in regions where individuals were more trusting. Jagannathan, Ma, and Zhang (2019) proved the phenomenon of risk reduction effect in large portfolios. Olivier (2019) showed that the risk preference could be measure by the "green bonds" prices. Using account level data, risk preference for bonds market was measured by Livingstona, Poon, and Zhou (2019). Their method was adopted by Butaru, Chen, Clark, Das, Lo, and Siddique (2016) for studying Chinese bonds market as well. Song, Yang, and Li (2004) believed that, in general, the relationship between the systematic risk and the average yield was as predicted by the Capital Asset Pricing Model (CAPM). From the individual point of view, however, the reverse risk return relationship was significant, which indicated that high risk was followed by low income. Shi and Cheng (2006) studied the returns and risks of SMEs in China and found that there was also a reverse risk return relationship. ElBannan (2015) put forward that although CAPM was one of the most useful and commonly used theory, the application of this model had been controversial in determining the required rate of return for securities. In theory, there was a positive correlation between risk and return, but many empirical studies got the opposite result. Theodossiou and Savva (2016) presented evidence to analyze the reasons for this contradiction. Wang (2011) empirically studied the relationship between returns and risks in Chinese and American stock markets. Yusaku and Sun (2016) confirmed the above results using high frequency future data. Ciarreta, Muniain, and Zarraga (2017) used high-frequency continuous intraday electricity auction price data from the EPEX market to study the relation between forecast realized volatility and abnormal returns. Zhao, Yuan, and Ren (2018) used HAR-CAW model to study short-term, medium-term, and long-term returns-risks relation between future market and spot market. Aras, Kocakoc, and Polat (2017) conducted a comparison study on the methods to predict returns-risks dynamics. Zhou, Hou, and Shao (2017) examined the static and dynamic volatility spillover effects and information spillover effects between the CSI 300 index futures return and CSI300 index return. Doojin (2017) tested the returns-risks relation in a market microstructure context by considering the inventory holding costs. Based on the CAPM model analysis of the stock market risk-return relationship, there are widespread theoretical and practical deficiencies. First of all, the CAPM model itself has strong assumptions, and the derived linear and positive risk-return relationship actually becomes questionable. Second, the test of the CAPM model will have a "joint test" problem. Since the operation of a listed company is generally continuous, its income fluctuations are sustained before the business situation has undergone major changes. Using this characteristic of stock return volatility, Haugen (1999) proposed a combination method based on stock historical returns to construct different risk characteristics, and solved the above two problems of CAPM model. He provided a new prospective for the study of risk return relationship in a stock market. His 
method examined the two combinations of the minimum risk portfolio and the maximum risk portfolio. Then, he held the two combinations for three months and repeated the above process. Zhao and Wang (2010) proposed a Monte Carlo method based on sampling. On the basis of an empirical research on 177 stocks in Shanghai and Shenzhen stock markets, they found that low risk was associated with high return and high risk with low return.

On the other hand, studies on the relationship between risk and return in China have some limitations. First, researchers in China have not fully considered the influence of different time intervals on the relationship between risk and income. Second, they have not explicitly considered the development situation and features of the Chinese stock market, of which the most important is the price limit system and non-tradable shares reform. Therefore, according to Zhao and Wang (2010), this paper used Haugen (1999)'s method and took the specific characteristics of China's stock market into account (by mainly considering the impact of price limits on the risk return relationship) to learn about the risk-return relationship of the Chinese stock market in different time periods.

This paper uses the composite construction method proposed by Haugen (1999) and the practical experience of Zhao and Wang (2010) in the application of the method. When using a small sample to analyze the relationship between short-term risks and returns, this paper finds that the relationship is not significant. Zhao and Wang (2010) believed that the yield of the lowest risk portfolio was significantly greater than that of the highest risk portfolio, which did not go in line with its conclusion. Nevertheless, when the average of the results is calculated, this conclusion is consistent with theirs. Regarding the relationship between long-term risks and returns, our conclusions confirm the positive relationship between risk and return, which further validates the conclusion of $\mathrm{Wu}, \mathrm{Zhao}$, and $\mathrm{Wu}$ (2002).

\section{Model and algorithms}

The model presented in this study is an application on the composite construction proposed by Haugen (1999) and the practical experience of Zhao and Wang (2010) in the application of composite construction method to the China stock market.

\subsection{Short term model of risk return relationship based on trading strategy}

First, it examines the short term by using the monthly interval. The following calculations are implemented by MATLAB $^{\circledast}$ (Yang, 2007). The procedure is as follows:

1) $\mathrm{N}$ stocks are sampled randomly from the stock market, and the covariance matrix of $\mathrm{N}$ stocks is calculated according to historical monthly rates of return.

$$
H=\left[\begin{array}{llll}
\sigma_{11} & \sigma_{12} & \cdots & \sigma_{1 N} \\
\sigma_{21} & \sigma_{22} & \cdots & \sigma_{2 N} \\
\vdots & \vdots & & \vdots \\
\sigma_{N 1} & \sigma_{N 2} & \cdots & \sigma_{N N}
\end{array}\right],
$$

where $\sigma_{i j}=\operatorname{Cov}\left(r_{i}, r_{j}\right)$ represents the covariance between stock $i$ and $j ; r_{i}, r_{j}$ is monthly rate of return of stock $i, j$, respectively. 
2) Using the mean variance model, this paper finds the least variance portfolio (minimum risk portfolio) in the last 24 months.

$$
\left\{\begin{array} { l } 
{ \operatorname { M i n } x ^ { T } H x } \\
{ \text { Subject to: } }
\end{array} \left\{\begin{array}{l}
0 \leq x \leq \text { weight } \times e, \\
e^{T} \times x=1
\end{array}\right.\right.
$$

where $x$ is the weight of each stock that satisfies the objective function; $x$ is a column vector; $e$ is a unit column vector; and weight is a weight constraint. If weight $=0.5$, the structured stock portfolio contains at least 20 stocks to eliminate the unsystematic risk.

3) Hold the three-month information of the stock portfolio found in Step 2 and calculate the monthly earnings of the stock portfolio denoted by $r_{p 1}, r_{p 2}, r_{p 3}$

$$
r_{p i}=x^{T} \times R_{i},
$$

where $R_{i}$ is the column vector of month $i$ 's stock yield.

4) Repeat Steps 1, 2, and 3 every three months to get a time series of minimum risk stock portfolio yield. Calculate its standard deviation $\delta_{L}$ which stands for the total risk by:

$$
\delta_{L}^{2}=\delta\left(x_{1} \times R_{1}+x_{2} \times R_{2}+\cdots+x_{n} \times R_{n}\right)^{2}=\sum_{i=1}^{n} \sum_{j=1}^{n} x_{i} x_{j} \sigma_{i j}
$$

and calculate the beta coefficient $\beta_{L}$ which stands for systematic risk by CAPM:

$$
r_{p i}=\alpha+\beta_{L} \times R_{m}+e_{i},
$$

where $r_{p i}$ stands for the monthly return of the portfolio, $\alpha$ stands for the excessive return of the portfolio, $\beta$ is the systematic risk that undertaken by the portfolio, $R_{m}$ is the return for market portfolio, and $e_{i}$ is the residual of the portfolio.

5) Let $M=-H$, repeat Steps $1,2,3$, and 4 to get a time series of maximum risk stock portfolio yield. Calculate its standard deviation $\delta_{H}$ which stands for the total risk and beta coefficient $\beta_{H}$ which stands for systematic risk by the method given in Step 3.

6) Repeat Steps 1, 2, 3, 4, and $5 \mathrm{~K}$ times. Verify whether the rate of return, standard deviation and beta coefficient of the two stock combinations were statistically significant by using a Wilcoxon Signed Rank Test.

\subsection{Long term model of risk return relationship based on trading strategy}

It considers the long term by using the quarterly interval as follows:

1) $N$ stocks are sampled randomly from the stock market, and the covariance matrix of $\mathrm{N}$ stocks is calculated according to historical quarterly rates of return.

$$
H=\left[\begin{array}{cccc}
\sigma_{11} & \sigma_{12} & \cdots & \sigma_{1 N} \\
\sigma_{21} & \sigma_{22} & \cdots & \sigma_{2 N} \\
\vdots & \vdots & & \vdots \\
\sigma_{N 1} & \sigma_{N 2} & \cdots & \sigma_{N N}
\end{array}\right],
$$


where $\sigma_{i j}=\operatorname{Cov}\left(r_{i}, r_{j}\right)$ represents the covariance between stock $i$ and $j ; r_{i}, r_{j}$ is quarterly rate of return of stock $i, j$ respectively.

2) Using the mean variance model, this paper finds the least variance portfolio (minimum risk portfolio) in the last 16 quarters.

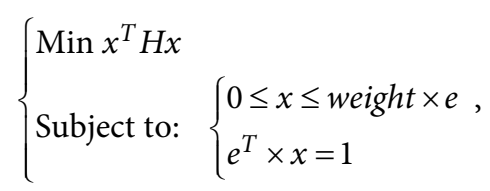

where $x$ is the weight of each stock that satisfies the objective function; $x$ is a column vector; $e$ is a unit column vector; weight is a weight constraint.

3) Hold the one-quarter information of the stock portfolio found in Step 2 and calculate the quarterly earnings of the stock portfolio denoted by $r_{p i}$

$$
r_{p i}=x^{T} \times R_{i},
$$

where $R_{i}$ is the column vector of stock yield in quarter $i$.

4) Repeat Steps 1, 2, and 3 every quarter to get a time series of minimum risk stock portfolio yield. Calculate its standard deviation $\delta_{L}$ which stands for the total risk by the method given in 3.1.1.

5) Let $M=-H$, repeat Steps $1,2,3$, and 4 to get a time series of maximum risk stock portfolio yield. Calculate its standard deviation $\delta_{H}$ which stands for the total risk and beta coefficient $\beta_{H}$ which stands for systematic risk by the method given in 3.1.1.

6) Repeat Steps 1, 2, 3, 4, and 5. Verify whether the mean, variance and value of the two stock combinations are statistically significant by using a Wilcoxon Signed Rank Test. The Figure 1 reflects the empirical method more intuitively and demonstrates the relationship between stock portfolio return and risk from both long-term and short-term perspectives.

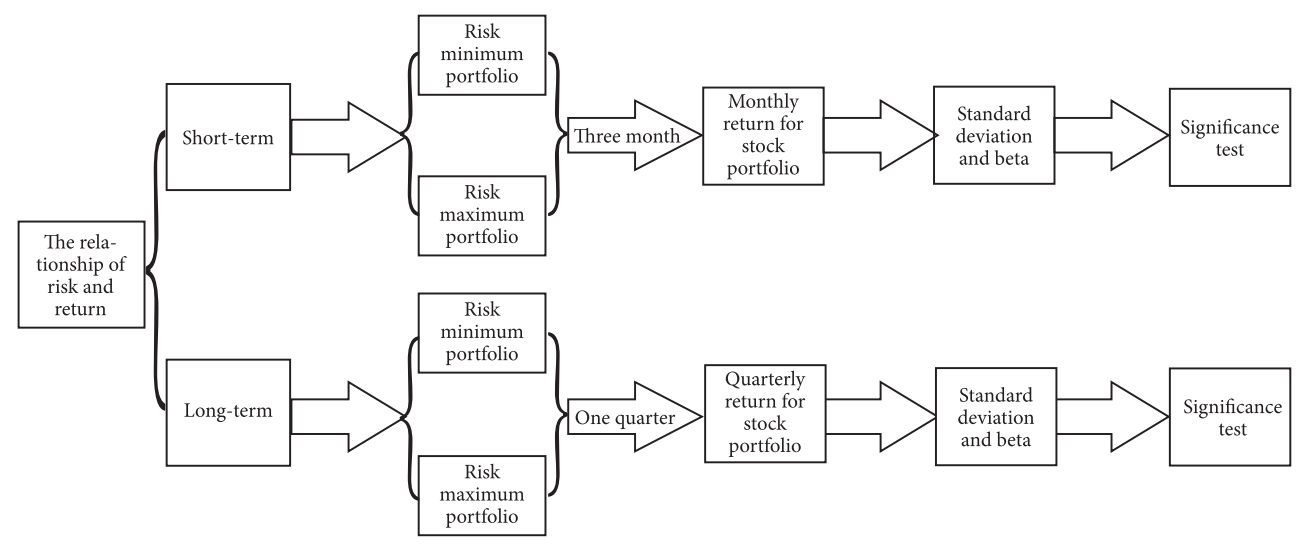

Figure 1. The flowchart of the study 


\section{Empirical results}

\subsection{Data and samples}

Considering that both the Shanghai and Shenzhen stock markets are in China's mainland, facing the same economic, political, and legal environments, they have significant correlation in investor structure (mainly individual investors) and governance structure etc. (Zhou, 2008). Taking into account the impact of the financial crisis, the present study found that the Shanghai and Shenzhen stock markets still have significant positive correlation, showing the same up and down characteristics (Table 1). The data collected are from January 1, 1997 to December 31, 2017, totaling 252 months, or 84 quarters. This paper selected the shares which have been listed on the Shanghai Stock Exchange since January 1, 1997, totaling 292 stocks, in which it excluded stocks with incomplete data:

- The stocks delisted during the survey interval were excluded because important data were missing.

- The stocks with long time suspension were also excluded. Because the long-time suspension is often due to major issues, the data are not continuous for ante- and postsuspension session, which may cause error if it uses interpolation methods.

Finally, it obtained 124 stocks with complete data. The data is selected from CSMAR database. The calculation of the quarterly return on cash dividends reinvested is as follows:

$$
R_{\text {quarter }}=\left(1+R_{\text {month } 1}\right) \times\left(1+R_{\text {month } 2}\right) \times\left(1+R_{\text {month } 3}\right)-1,
$$

where $R_{\text {month } 1}, R_{\text {month } 2}, R_{\text {month } 3}$ are the monthly incomes of cash dividends reinvested.

The graph below shows the volatility of the Shanghai Stock Exchange and the US Dow Jones Index during the sample period. The Shanghai Stock Exchange is much more volatile than the US Dow Jones Index.

Table 2 presents the descriptive statistics for the sample while Table 3 show the Table 3. Comparison of the market capitalization of China, US and UK in 2018.

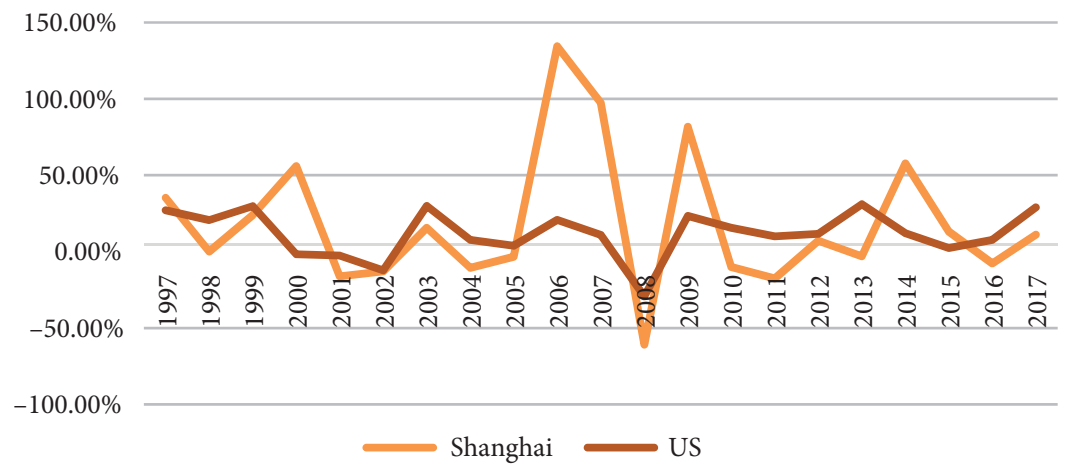

Figure 2. Stock market's fluctuations 
Table 1. Correlation between Shanghai and Shenzhen stock markets

\begin{tabular}{|c|c|}
\hline Variable & Coefficient and t-statistic \\
\hline \multirow{2}{*}{$\mathrm{C}$} & 0.0187 \\
& $(0.2593)$ \\
\hline \multirow{2}{*}{ Shanghai } & 1.1821 \\
& $(8.8262)$ \\
\hline
\end{tabular}

Table 2. Descriptive statistics of basic characteristics of the sample data

\begin{tabular}{|c|c|c|c|c|}
\hline Year & Mean & Standard deviation & Skewness & Kurtosis \\
\hline 1997 & 0.030 & 0.031 & 0.306 & -0.361 \\
\hline 1998 & 0.015 & 0.029 & 0.661 & 1.083 \\
\hline 1999 & 0.024 & 0.028 & 1.045 & 2.042 \\
\hline 2000 & 0.047 & 0.026 & 1.183 & 4.925 \\
\hline 2001 & -0.016 & 0.016 & 0.647 & 1.908 \\
\hline 2002 & -0.016 & 0.016 & 0.916 & 2.701 \\
\hline 2003 & -0.010 & 0.024 & 0.535 & 0.803 \\
\hline 2004 & -0.012 & 0.024 & -0.582 & 3.102 \\
\hline 2005 & -0.008 & 0.023 & 0.745 & 1.465 \\
\hline 2006 & 0.059 & 0.036 & 0.986 & 1.458 \\
\hline 2007 & 0.110 & 0.038 & 0.671 & 1.594 \\
\hline 2008 & -0.061 & 0.026 & 0.755 & 2.333 \\
\hline 2009 & 0.082 & 0.028 & 0.575 & 0.908 \\
\hline 2010 & 0.009 & 0.027 & 0.666 & 0.450 \\
\hline 2011 & -0.023 & 0.021 & 0.928 & 2.329 \\
\hline 2012 & 0.010 & 0.023 & 1.283 & 3.878 \\
\hline 2013 & 0.015 & 0.031 & 1.213 & 4.785 \\
\hline 2014 & 0.035 & 0.024 & 0.967 & 2.407 \\
\hline 2015 & 0.044 & 0.033 & 0.574 & 0.988 \\
\hline 2016 & -0.004 & 0.018 & 0.491 & 1.143 \\
\hline 2017 & -0.009 & 0.028 & 0.788 & 0.714 \\
\hline
\end{tabular}

Table 3. Comparison of the market capitalization of China, US and UK in 2018 (unit: hundred million US dollars)

\begin{tabular}{|c|c|}
\hline Country & Stock market capitalization \\
\hline China & 64759 \\
\hline US & 377763 \\
\hline UK & 161395 \\
\hline
\end{tabular}




\subsection{Analysis of short-term risk-return relationship}

This paper randomly selected 50 stocks from 124 which were then constructed according to the previous theory. Firstly, it simulated 100 times at the interval of one month, controlling the weight of each stock to less than or equal to $5 \%$ to ensure that the number of stocks was at least 20. Table 4 shows the simulation results (the first 10 are listed).

Table 4. Simulation results

\begin{tabular}{|c|c|c|c|c|c|c|}
\hline \multirow{2}{*}{$\begin{array}{c}\text { Simulation } \\
\text { runs }\end{array}$} & \multicolumn{2}{|c|}{ Rate of return } & \multicolumn{2}{c|}{ Total risk } & \multicolumn{2}{c|}{ Systematic risk } \\
\cline { 2 - 7 } & $R_{L}$ & $R_{H}$ & $\delta_{L}$ & $\delta_{H}$ & $\beta_{L}$ & $\beta_{H}$ \\
\hline 1 & 0.015 & 0.014 & 0.095 & 0.111 & 0.959 & 1.088 \\
\hline 2 & 0.014 & 0.014 & 0.098 & 0.112 & 0.995 & 1.110 \\
\hline 3 & 0.014 & 0.016 & 0.096 & 0.114 & 0.961 & 1.115 \\
\hline 4 & 0.015 & 0.013 & 0.099 & 0.112 & 0.992 & 1.120 \\
\hline 5 & 0.013 & 0.015 & 0.097 & 0.111 & 0.979 & 1.084 \\
\hline 6 & 0.014 & 0.015 & 0.098 & 0.112 & 0.983 & 1.086 \\
\hline 7 & 0.015 & 0.013 & 0.095 & 0.111 & 0.934 & 1.083 \\
\hline 8 & 0.014 & 0.013 & 0.099 & 0.110 & 1.004 & 1.083 \\
\hline 9 & 0.013 & 0.014 & 0.097 & 0.110 & 0.943 & 1.079 \\
\hline 10 & 0.013 & 0.014 & 0.096 & 0.112 & 0.957 & 1.086 \\
\hline
\end{tabular}

Notes: The first 10 simulation runs; the sample size is 50 ; the weight constraint is 0.05 ; the interval is month.

In Table $4, R_{L}, R_{H}, \delta_{L}, \delta_{H}$ represent the rate of return of the minimum and maximum risk portfolio, and standard deviation of the minimum and maximum risk portfolio, respectively. The minimum risk portfolio and the maximum risk portfolio are calculated on the basis of the monthly rate of return considering cash dividends reinvestment in the past 24 months. $\beta$ is the systematic risk of the stock portfolio which is calculated based on the monthly stock portfolio returns and the monthly earnings of the Shanghai Composite Index over the same period. $\beta_{L} \times \beta_{H}$ represent the systematic risk of the minimum risk portfolio and the maximum risk portfolio, respectively. Table 4 shows that whether it is the maximum risk combination or the minimum risk combination, the systematic risk is very close to 1 , which indicates that the unsystematic risk is well eliminated and also confirms the correctness of the construct portfolio we used. The total risk and systematic risk of the minimum risk combination are obviously smaller than those of the maximum risk combination, while there is no clear relationship in the yield. In Table $5, \delta_{L}, \delta_{H}$ represent standard deviation of the minimum and maximum risk portfolio, respectively. In order to check on the statistical significance of the simulation results, this paper conducted Wilcoxon Signed Rank Tests for the 100 simulation results. The test results are shown in Table 5.

According to Table 5, statistically speaking, the total risk and systemic risk of the portfolio with the lowest risk are significantly lower than those with the highest risk. In terms of return rate, however, no significant difference was found between the two $(P=0.909)$. This result 
is inconsistent with the research conclusion of Zhao and Wang (2010), who found that the return rate of the portfolio with the lowest risk is significantly larger than that of the portfolio with the highest risk and believed that there is an inverse risk return relationship in the stock market). When results of the 100 simulations were averaged, the return rate of the portfolio with the lowest risk was greater than that of the portfolio with the highest risk (Figure 3).

Table 5. Wilcoxon signed rank test

\begin{tabular}{|c|c|c|c|}
\hline Original hypothesis & Alternative hypothesis & P-value & Conclusion \\
\hline$\delta_{L} \geq \delta_{H}$ & $\delta_{L}<\delta_{H}$ & 0.023 & Reject H0 \\
\hline$\beta_{L} \geq \beta_{H}$ & $\beta_{L}<\beta_{H}$ & 0.029 & Reject H0 \\
\hline
\end{tabular}

Note: The significance level is $5 \%$.

As a next step, it changed the sample size to 100 stocks from 124 which were then constructed according to the previous theory. The results are presented in Table 6 and 7. First, it simulated 100 times at the interval of one month, limiting the weight of each stock to less than or equal to 5\%. Meanwhile, it also conducted Wilcoxon Signed Rank Tests for the 100 simulation results.

In Table $6, R_{L}, R_{H}, \delta_{L}, \delta_{H}$ represent the rate of return of the minimum and maximum risk portfolio, and standard deviation of the minimum and maximum risk portfolio, respectively. The minimum risk portfolio and the maximum risk portfolio are calculated on the basis of the monthly rate of return considering cash dividends reinvestment in the past 24 months. $\beta$ is the systematic risk of the stock portfolio which is calculated based on the monthly stock portfolio returns and the monthly earnings of the Shanghai Composite Index over the same period. $\beta_{L} \times \beta_{H}$ represent the systematic risk of the minimum risk portfolio and the maximum risk portfolio, respectively.

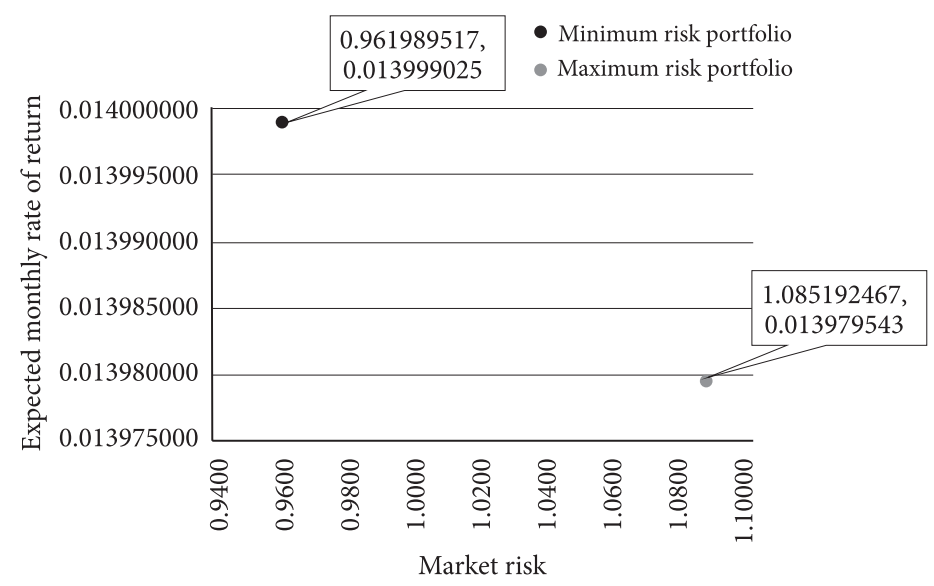

Figure 3. Reverse risk return relationship (the sample size is 50; weight constraint is 0.05 ; the interval is month) 
Table 6. Simulation results

\begin{tabular}{|c|c|c|c|c|c|c|}
\hline \multirow{2}{*}{$\begin{array}{c}\text { K-th } \\
\text { simulation } \\
\text { run }\end{array}$} & \multicolumn{2}{|c|}{ Rate of return } & \multicolumn{2}{c|}{ Total risk } & \multicolumn{2}{c|}{ Systematic risk } \\
\cline { 2 - 7 } & $R_{L}$ & $R_{H}$ & $\delta_{L}$ & $\delta_{H}$ & $\beta_{L}$ & $\beta_{H}$ \\
\hline 1 & 0.012 & 0.012 & 0.092 & 0.106 & 0.925 & 1.056 \\
\hline 2 & 0.012 & 0.013 & 0.094 & 0.109 & 0.944 & 1.092 \\
\hline 3 & 0.011 & 0.013 & 0.093 & 0.107 & 0.929 & 1.076 \\
\hline 4 & 0.013 & 0.014 & 0.094 & 0.109 & 0.936 & 1.085 \\
\hline 5 & 0.013 & 0.013 & 0.092 & 0.109 & 0.916 & 1.075 \\
\hline 6 & 0.011 & 0.013 & 0.091 & 0.108 & 0.911 & 1.082 \\
\hline 7 & 0.014 & 0.012 & 0.095 & 0.109 & 0.943 & 1.063 \\
\hline 8 & 0.014 & 0.013 & 0.093 & 0.110 & 0.932 & 1.103 \\
\hline 9 & 0.011 & 0.012 & 0.090 & 0.108 & 0.896 & 1.089 \\
\hline 10 & 0.012 & 0.012 & 0.095 & 0.108 & 0.954 & 1.081 \\
\hline
\end{tabular}

Note: The first 10 simulation runs out of 100 ; the weight constraint is 0.05 ; the interval is a month.

Table 7. Wilcoxon signed rank test

\begin{tabular}{|c|c|c|c|}
\hline Original hypothesis $\mathrm{H}_{0}$ & Alternative hypothesis $\mathrm{H}_{1}$ & P-value & Conclusion \\
\hline$\delta_{L} \geq \delta_{H}$ & $\delta_{L}<\delta_{H}$ & 0.012 & Reject H0 \\
\hline$\beta_{L} \geq \beta_{H}$ & $\beta_{L}<\beta_{H}$ & 0.015 & Reject H0 \\
\hline
\end{tabular}

Note: The significance level is $5 \%$.

In Table $7, \delta_{L}, \delta_{H}$ represent standard deviation of the minimum and maximum risk portfolio, respectively. In order to check on the statistical significance of the simulation results, this paper conducted Wilcoxon Signed Rank Tests for the 100 simulation results. At the $5 \%$ level, the original hypothesis is rejected; but at the $1 \%$ level, the original hypothesis cannot be rejected. That is to say, when the confidence level is $1 \%$, it cannot be said that the risk of the portfolio with low risk stocks is lower than that of the portfolio with high stock builds. According to Table 6 and 7, the total risk and systematic risk of the minimum risk portfolio are significantly smaller than those of maximum risk portfolio. However, after the average of the 100 simulation results was taken, the risk return-relationship became positive, which means that in the short run, with the increase of the number of shares in the stock portfolio, the positive risk-return relationship became significant. This is because more stocks in the portfolio will diverse the abnormal fluctuation caused by irrational investors.

\subsection{Analysis of long-term risk-return relationship}

This paper randomly selected 50 stocks from 124 samples which were then constructed according to the previous theory. This time, it simulated 100 times at the interval of one quarter. In Table $8, \delta_{L}, \delta_{H}$ represent standard deviation of the minimum and maximum risk portfolio, respectively. In order to check on the statistical significance of the simulation results, it conducted Wilcoxon Signed Rank Tests for the 100 simulation results. 
Table 8. Wilcoxon signed rank test

\begin{tabular}{|c|c|c|c|}
\hline Original hypothesis $\mathrm{H}_{0}$ & Alternative hypothesis $\mathrm{H}_{1}$ & P-value & Conclusion \\
\hline$R_{L} \geq R_{H}$ & $R_{L}<R_{H}$ & 0.014 & Reject H0 \\
\hline$\delta_{L} \geq \delta_{H}$ & $\delta_{L}<\delta_{H}$ & 0.047 & Reject H0 \\
\hline$\beta_{L} \geq \beta_{H}$ & $\beta_{L}<\beta_{H}$ & 0.039 & Reject H0 \\
\hline
\end{tabular}

Note: The significance level is $5 \%$.

At the $5 \%$ level, the original hypothesis is rejected; but at the $1 \%$ level, the original hypothesis cannot be rejected. That is to say, when the confidence level is $1 \%$, it cannot be said that the risk of the portfolio with low risk stocks is lower than that of the portfolio with high stock builds. According to Table 8, the total risk and systematic risk of the minimum risk portfolio are significantly smaller than those of the maximum risk portfolio, while in terms of the yield, and the yield of the minimum risk portfolio is significantly smaller than that of the maximum risk portfolio. It shows that high risk is associated with high income and low risk with low income, which is consistent with the positive risk-return relationship derived from the CAPM. After the average of the simulation results was taken, as shown in Figure 4, the correlation between high risk with high yield and low risk with low income is established. Thus, in the long run (quarter time), the ups and downs effectively inhibit speculation and investors' tendency to invest rationally.

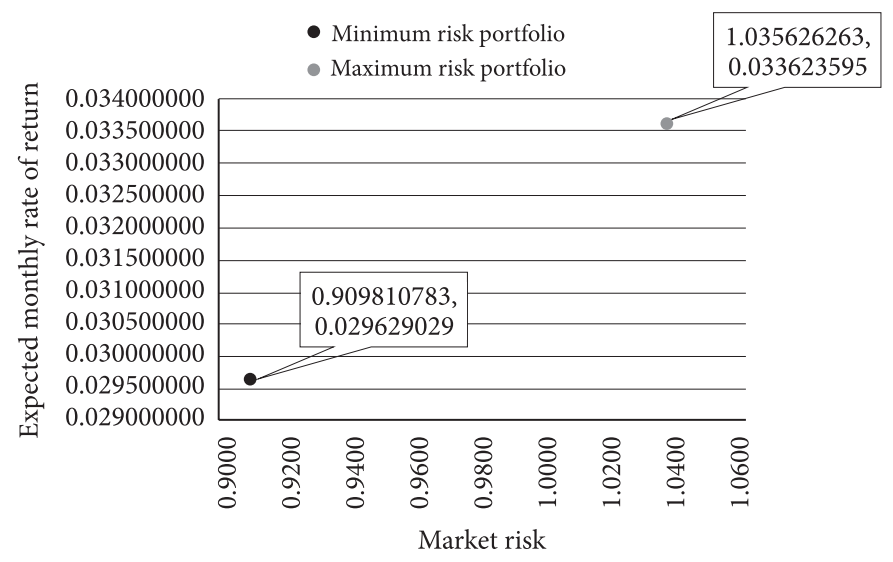

Figure 4. Positive risk-return relationship (the sample size is 50; weight constraint is 0.05 ; the interval is quarter)

Then, this paper extracted 100 stocks, controlling the weight of each stock to less than or equal to $5 \%$ to ensure that the number of stocks was $20 \sim 100$. The first 20 simulation results and the Wilcoxon Signed Rank Test are shown in Table 9 and 10, respectively. The total risk and systematic risk of the minimum risk portfolio are significantly smaller than those of the maximum risk portfolio, while in terms of the yield, the yield of the minimum risk portfolio is significantly smaller than that of the maximum risk portfolio. Therefore, in the 
long run, the simple size has little effect on the conclusion, but it has a great impact on the significance. As we can see from Table 11 that as sample size increases, the $\mathrm{P}$ value decreases and the significance increases. That is to say, with the increase in the number of shares, the effectiveness of the stock market increases.

Table 9. Simulation results

\begin{tabular}{|c|c|c|c|c|c|c|}
\hline \multirow{2}{*}{$\begin{array}{c}\text { K-th } \\
\text { simulation } \\
\text { run }\end{array}$} & \multicolumn{2}{|c|}{ Rate of return } & \multicolumn{2}{c|}{ Total risk } & \multicolumn{2}{c|}{ Systematic risk } \\
\cline { 2 - 7 } & $R_{L}$ & $R_{H}$ & $\delta_{L}$ & $\delta_{H}$ & $\beta_{L}$ & $\beta_{H}$ \\
\hline 1 & 0.024 & 0.031 & 0.196 & 0.216 & 0.882 & 1.063 \\
\hline 2 & 0.024 & 0.028 & 0.210 & 0.215 & 0.937 & 1.049 \\
\hline 3 & 0.023 & 0.033 & 0.207 & 0.215 & 0.908 & 1.051 \\
\hline 4 & 0.024 & 0.029 & 0.204 & 0.217 & 0.905 & 1.041 \\
\hline 5 & 0.022 & 0.029 & 0.199 & 0.218 & 0.891 & 1.067 \\
\hline 6 & 0.021 & 0.028 & 0.200 & 0.212 & 0.884 & 1.059 \\
\hline 7 & 0.023 & 0.032 & 0.203 & 0.220 & 0.892 & 1.048 \\
\hline 8 & 0.023 & 0.030 & 0.204 & 0.214 & 0.902 & 1.035 \\
\hline 9 & 0.024 & 0.027 & 0.207 & 0.210 & 0.918 & 1.030 \\
\hline 10 & 0.024 & 0.033 & 0.205 & 0.216 & 0.900 & 1.090 \\
\hline
\end{tabular}

Note: The first 10 simulation runs of 100 ; the weight constraint is 0.05 ; the interval is quarter.

In Table 9, $R_{L}, R_{H}, \delta_{L}, \delta_{H}$ represent rate of return of the minimum and maximum risk portfolio,and standard deviation of the minimum and maximum risk portfolio, respectively. $\beta_{L}, \beta_{H}$ represent the systematic risk of the minimum risk portfolio and the maximum risk portfolio, respectively.

Table 10. Wilcoxon signed rank test

\begin{tabular}{|c|c|c|c|}
\hline Original hypothesis $\mathrm{H}_{0}$ & Alternative hypothesis $\mathrm{H}_{1}$ & P-value & Conclusion \\
\hline$R_{L} \geq R_{H}$ & $R_{L}<R_{H}$ & 0.046 & Reject H0 \\
\hline$\delta_{L} \geq \delta_{H}$ & $\delta_{L}<\delta_{H}$ & 0.041 & Reject H0 \\
\hline$\beta_{L} \geq \beta_{H}$ & $\beta_{L}<\beta_{H}$ & 0.023 & Reject H0 \\
\hline
\end{tabular}

Note: The significance level is $5 \%$.

In Table $10, \delta_{L}, \delta_{H}$ represent standard deviation of the minimum and maximum risk portfolio, respectively. In order to check on the statistical significance of the simulation results, it conducted Wilcoxon Signed Rank Tests for the 100 simulation results. At the 5\% level, the original hypothesis is rejected; but at the $1 \%$ level, the original hypothesis cannot be rejected. That is to say, when the confidence level is $1 \%$, it cannot be said that the risk of the portfolio with low risk stocks is lower than that of the portfolio with high stock builds. And it does not mean that low-risk portfolios have higher yields. 
Table 11. Comparison of $\mathrm{P}$ values with different sample sizes (weight restriction is 0.05)

\begin{tabular}{|c|c|c|}
\hline \multirow{2}{*}{ Sample size } & \multicolumn{2}{|c|}{ Inspection interval } \\
\cline { 2 - 3 } & Month & Quarter \\
\hline 50 & 0.315 & 0.139 \\
\hline 100 & 0.252 & 0.046 \\
\hline
\end{tabular}

Table 11 shows the effect of comparing the length of different time intervals and the number of samples on the value of $t$ in the case where the constraint weights are the same. $t$ values decrease (and therefore the statistics are getting more significant) as sample size increases, indicating that the effectiveness of the stock market is gradually enhanced by introducing more investable underlings.

\subsection{Comparison of risk and return relationship for short and long term with all 124 stocks considered and the weight constraint is $\mathbf{0 . 0 5}$}

The simulation was conducted at monthly and quarterly intervals respectively, and the simulation results are shown in Table 12.

Table 12. Empirical results (the number of stocks is 124; the weight constraint is 0.05 )

\begin{tabular}{|l|c|c|c|c|c|c|}
\hline \multirow{3}{*}{ Interval } & \multicolumn{2}{|c|}{ Rate of return } & \multicolumn{2}{c|}{ Total risk } & \multicolumn{2}{c|}{ Systematic risk } \\
\cline { 2 - 7 } & $R_{L}$ & $R_{H}$ & $\delta_{L}$ & $\delta_{H}$ & $\beta_{L}$ & $\beta_{H}$ \\
\hline Month & 0.012 & 0.012 & 0.092 & 0.108 & 0.921 & 1.080 \\
\hline Quarter & 0.021 & 0.026 & 0.204 & 0.212 & 0.897 & 1.056 \\
\hline
\end{tabular}

Table 12 shows the comparison of portfolio return, total risk and system risk at different time intervals under the same circumstances. With all 124 stocks considered, this paper simulated 100 times at the interval of one month and one quarter, respectively, controlling again the weight to $5 \%$. As the results show, at the monthly internal, the expected rate of return of the minimum risk portfolio is equal to that of the maximum risk portfolio, which is inconsistent with the conclusion that high risk is associated with high income and low risk with low income. However, for the quarterly interval, the expected rate of return of the maximum risk portfolio is larger than that of the minimum risk portfolio.

\subsection{Comparison of risk and return relationship for short and long term with all 124 stocks considered and the weight constraint varies from 0.02 to 0.05 at an increment of 0.01}

The results above were obtained with the same weight constraint. Next, the weight constraint was changed from 0.02 to 0.05 at an increment of 0.01 . Using 100 stocks, it simulated 100 times. The Wilcoxon Signed Rank Test results are shown in Table 13. 
Table 13. Wilcoxon signed rank test

\begin{tabular}{|c|c|c|c|}
\hline Original hypothesis $\mathrm{H}_{0}$ & Alternative hypothesis $\mathrm{H}_{1}$ & P-value & Conclusion \\
\hline$R_{L} \geq R_{H}$ & $R_{L}<R_{H}$ & 0.010 & Reject H0 \\
\hline$\delta_{L} \geq \delta_{H}$ & $\delta_{L}<\delta_{H}$ & 0.007 & Reject H0 \\
\hline$\beta_{L} \geq \beta_{H}$ & $\beta_{L}<\beta_{H}$ & 0.005 & Reject H0 \\
\hline
\end{tabular}

Note: The significance level is $5 \%$, at the internal of month.

In Table 13, $\delta_{L}, \delta_{H}$ represent standard deviation of the minimum and maximum risk portfolio, respectively. In order to check on the statistical significance of the simulation results, this paper conducted Wilcoxon Signed Rank Tests for the 100 simulation results. The short-term test results are shown in Table 13. The expected rate of return of the minimum risk portfolio is much smaller than that of the maximum risk portfolio. Comparing this with previous test results, we found that the smaller the weight constraint and the more the number of stocks portfolio, the smaller the $\mathrm{P}$ value. Tables 13 shows that in the case of quarterly intervals, the expected rate of return of the minimum risk portfolio is also much smaller than that of the maximum risk portfolio. This finding goes in line with previous test results What is more, under the same conditions (the same number of weights and sampling), the $\mathrm{P}$ value for the quarterly interval is smaller than that for the monthly interval, which means $R_{L}<R_{H}$ is more readily accepted. The expected return rate of the portfolio with the lowest risk and that of the portfolio with the highest risk were compared under different time intervals and samples. Furthermore, the weight constraint was changed to increase from 0.02 to 0.05 at an interval of 0.01 , and the monthly and quarterly time intervals were also examined. In Table $14, \delta L, \delta H$ represent standard deviation of the minimum and maximum risk portfolio, respectively. To check on the statistical significance of the simulation results, Wilcoxon Signed Rank Tests were conducted for the 100 simulation results.

Table 14. Wilcoxon signed rank test

\begin{tabular}{|c|c|c|c|}
\hline Original hypothesis $\mathrm{H}_{0}$ & Alternative hypothesis $\mathrm{H}_{1}$ & P-value & Conclusion \\
\hline$R_{L} \geq R_{H}$ & $R_{L}<R_{H}$ & 0.046 & Reject H0 \\
\hline$\delta_{L} \geq \delta_{H}$ & $\delta_{L}<\delta_{H}$ & 0.032 & Reject H0 \\
\hline$\beta_{L} \geq \beta_{H}$ & $\beta_{L}<\beta_{H}$ & 0.016 & Reject H0 \\
\hline
\end{tabular}

Note: The significance level is $5 \%$, at the internal of quarter.

At the $5 \%$ level, the original hypothesis is rejected; but at the $1 \%$ level, the original hypothesis cannot be rejected. That is to say, when the confidence level is $1 \%$, it cannot be said that the risk of the portfolio with low risk stocks is lower than the risk of the portfolio with high stock builds. And it does not mean that low-risk portfolios have higher yields. Table 14 
indicates that the expected return rate of the stock portfolio with the least risk is significantly lower than that of the stock portfolio with the highest risk if the time interval is a quarter.

Table 15 shows the effect of comparing the length of different time intervals and the weight of different time intervals on the value of $t$ in the case of the same number of samples. Data in Table 15 confirms that in the short term, the risk-return relationship is uncertain in the Chinese stock market.

Table 15. Comparison of $\mathrm{P}$ values under different weight constraints (sample size is 100)

\begin{tabular}{|c|c|c|}
\hline \multirow{2}{*}{ Weight constraints } & \multicolumn{2}{|c|}{ Frequencies } \\
\cline { 2 - 3 } & Monthly & Quarterly \\
\hline 0.02 & 0.010 & 0.046 \\
\hline 0.03 & 0.014 & 0.038 \\
\hline 0.04 & 0.016 & 0.033 \\
\hline 0.05 & 0.250 & 0.046 \\
\hline
\end{tabular}

Finally, the change in stock market risk-return relationship is analysed as the weights are adjusted. At the monthly interval, three empirical results are obtained. First, when the weight restriction is $0.02, R_{L}<R_{H}$ is obviously established. That is to say, the rate of return of the minimum risk portfolio is significantly smaller than that of the maximum risk portfolio. Second, when the weight restriction is 0.03 or $0.04, R_{L}>R_{H}$ is established. That is to say, the rate of return of the minimum risk portfolio is significantly larger than that of the maximum risk portfolio. Third, when the weight restriction is 0.05 , there is no statistically significant difference between $R_{L}$ and $R_{H}$.

\section{Discussion}

Results of the present study are of importance for investors, policymakers, and regulators because the rational reactions under different market situation are explored. First of all, individual investors and buy-side institutional investors should understand that the value investment is still an important method for their investment strategies even when the market operates in chaos. For sell-side institutional investors, this paper's results would still be beneficial regarding balanced risks and returns of their products. Furthermore, policymakers should be aware that it is their obligation to keep the stock market in a standardized and transparent manner, which enables investors to make a rational choice between long-term and short-term risks and returns, thus making the market and the formulation of regulatory policies more mature. In addition, regulators could have a clearer understanding of investors' trading behaviours, thus formulating more accurate policies. Finally, since the maturity cycle of a market is relatively long, regulators can dynamically evaluate the state of the market using the method suggested in this paper, so as to issue policies more in line with the actual situation of the market. 


\section{Conclusions}

This paper adopted composite construction and its application to the Chinese stock market. Using stocks data listed on the Shanghai A share market, it selected the stocks which have been listed on the Shanghai Stock Exchange for the period from January 1, 1997 to December 31,2017 . Then, based on the mean variance model of the portfolio structure, it analyzed the long-term and short-term risk-return relationship and sample size, followed by an analysis of the simulation results using the Wilcoxon Signed Rank Test. The analysis results show that in the short term, the relationship between risk and return is more complicated, which illustrates the complexity of China's stock market. In the long run, there is a significant positive relationship between risk and return, which is consistent with the description of the CAPM model. When the short-term average yield is taken into consideration [or "Regarding the short... yield"], our conclusion is not consistent with the CAPM model in that it shows the stocks with lower risk have higher yields. Nevertheless, when long term is taken into consideration [or "regarding long term"], our conclusions satisfy the CAPM model, that is, the risks are positively correlated with the returns. However, the number of samples in this paper is still small, and the long-term and short-term divisions could have more changes. These two limitations may affect the conclusion. Therefore, different samples and different time divisions need to be studied in future research.

\section{Acknowledgements}

The authors thank Dr Martinkute Kaulienè and two anonymous reviewers for their help and crucial comments.

\section{Funding}

This work was supported by the $<$ National Social Science Foundation of China $>$ under Grant [18BJL075]; < Sichuan University Innovation fund > under Grant [2018hhs-49]; < Fundamental Research Funds for the Central Universities> under Grant [J JBK1902054]; <National Natural Science Foundation of China>under Grant [71473204]; < Sichuan education quality reform project> under Grant [JG2018-280].

\section{Author contributions}

$\mathrm{CL}$ and HS conceived the study and were responsible for the design and development of the data analysis. LW were responsible for data collection and analysis. HS was responsible for data interpretation. MG wrote the first draft of the article.

\section{Disclosure statement}

The authors declare that we did not have any competing financial, professional, or personal interests from other parties. 


\section{References}

Aras, S., Kocakoç, İpek, \& Polat, C. (2017). Comparative study on retail sales forecasting between single and combination methods. Journal of Business Economics and Management, 18(5), 803-832. https://doi.org/10.3846/16111699.2017.1367324

Barberis, B., Greenwood, R., Lawrence, J., \& Shleifer, A. (2015). X-CAPM: An extrapolative capital asset pricing model. Journal of Financial Economics, 115(1), 1-24. https://doi.org/10.1016/j.jfineco.2014.08.007

Benlagha, N., \& Chargui, S. (2017). Range-based and GARCH volatility estimation: Evidence from the French asset market. Global Finance Journal, 32, 149-165. https://doi.org/10.1016/j.gfj.2016.04.001

Baležentis, T., Štreimikienè, D., Melnikienè, R., \& Yu, Z. (2017). Non-parametric analysis of yield risk in Lithuanian crop farming. Journal of Business Economics and Management, 18, 2017(3), https://doi.org/10.3846/16111699.2017.1322633

Butaru, F., Chen, Q., Clark, B., Das, S., Lo, A. W., \& Siddiqu, A. (2016). Risk and risk management in the credit card industry. Journal of Banking \& Finance, 72, 218-239. https://doi.org/10.1016/j. jbankfin.2016.07.015

Chan, K., Wang, J., \& Wei, K. C. J. (2004). Underpricing and long-term performance of IPOs in China. Journal of Corporate Finance, 10(3), 409-430. https://doi.org/10.1016/S0929-1199(03)00023-3

Chen, Q., \& Li, Z. (2008). Research of CAPM on liquidity adjustment in China. The Journal of Quantitative \& Technical Economics, 25(6), 66-78.

Christensen, B. J., Nielsen, M. O., \& Zhu, J. (2010). Long memory in stock market volatility and the volatility-in-mean effect: The FIEGARCH-M model. Journal of Empirical Finance, 17(3), 460-470. https://doi.org/10.1016/j.jempfin.2009.09.008

Ciarreta, A., Muniain, P., \& Zarraga, A. (2017). Modeling and forecasting realized volatility in German-Austrian continuous intraday electricity prices. Journal of Forecasting, 36(6).

https://doi.org/10.1002/for.2463

Cox, D. R., \& Peterson, D. R. (1994). Stock returns following large one-day declines: Evidence on shortterm reversals and longer-term performance. Journal of Finance, 49(1), 255-267. https://doi.org/10.1111/j.1540-6261.1994.tb04428.x

Doojin, R. (2017). Comprehensive market microstructure model: considering the inventory holding costs. Journal of Business Economics and Management, 18(2), 183-201. https://doi.org/10.3846/16111699.2017.1286380

ElBannan, M. (2015). The capital asset pricing model: an overview of the theory. International Journal of Economics and Finance, 7(1), 216-228. https://doi.org/10.5539/ijef.v7n1p216

Fama, E. F., \& French, K. R. (1992). The cross-section of expected stock returns. The Journal of Finance, 47(2), 427-465. https://doi.org/10.1111/j.1540-6261.1992.tb04398.x

Fan, X., \& Du. D. (2017). The Spillover effect between CSI500 index futures market and the spot market: evidence from high frequency data in 2015. China Finance Review International, 7(2), 249-272. https://doi.org/10.1108/CFRI-08-2016-0103

Froot, K. A., Scharfstein, D. S., \& Stein, J. C. (1992). Herd on the street: Informational inefficiencies in a market with short-term speculation. Journal of Finance, 47(4), 1461-1484. https://doi.org/10.1111/j.1540-6261.1992.tb04665.x

Ghysels, E., Santa-Clara, P., \& Valkanov, R. (2005). There is a risk-return trade-off after all. Journal of Financial Economics, 76(3), 509-548. https://doi.org/10.1016/j.jfineco.2004.03.008

Guo, C., \& Ling, K. (2004). Statistical analysis of the relationship between risk and return in China stock market. Journal of Lanzhou University (Social Sciences), 32(6), 92-94. 
Haugen, R. A. (1999). The new finance: the case against efficient markets contemporary issues in finance (pp. 97-103). Prentice Hall.

Hong, M., Ramchander, R., Wang, T., \& Yang, D. (2017). Role of index futures on China's stock markets: Evidence from price discovery and volatility spillover. Pacific-Basin Finance Journal, 44, 13-26. https://doi.org/10.1016/j.pacfin.2017.05.003

Hou, K., \& Loh, R. (2016). Have we solved the idiosyncratic volatility puzzle. Journal of Financial Economics, 121(1), 167-194. https://doi.org/10.1016/j.jineco.2016.02.013

Jagannathan, R., \& Ma, T., \& Zhang, J. (2019). A note on "Risk reduction in large portfolios: Why imposing the wrong constraints helps". Journal of Finance, 74(5). https://doi.org/10.1111/jofi.12824

Jouini, E., \& Napp, C. (2011). Unbiased disagreement in financial markets, waves of pessimism and the risk-return trade-off. Review of Finance, 15(3), 575-601. https://doi.org/10.1093/rof/rfq002

Lundblad, C. (2007). The risk return tradeoff in the long run: 1836-2003. Journal of Financial Economics, 85(1), 123-150. https://doi.org/10.1016/j.jfineco.2006.06.003

Li, B., \& Wu, S. (2003). An empirical study of the effectiveness and applicability of CAPM - a test of Shanghai stock market. China Economic Studies, 2, 36-41.

Lins, K. V., Servaes, H., \& Tamayo, A. (2017). Social capital, trust, and firm performance: the value of corporate social responsibility during the financial crisis. The Journal of Finance, 72, 1785-1824. https://doi.org/10.1111/jofi.12505

Livingstona, M., Poon, W. P. H., \& Zhou, L. (2019). Are Chinese credit ratings relevant? A study of the Chinese bond market and credit rating industry. Journal of Banking \& Finance, 87, 216-232. https://doi.org/10.1016/j.jbankfin.2017.09.020

Olivier, D. (2019). The effect of pro-environmental preferences on bond prices: Evidence from green bonds. Journal of Banking \& Finance, 98, 39-60. https://doi.org/10.1016/j.jbankfin.2018.10.012

Rickett, L., \& Datta, P. (2018). Beauty-contests in the age of financialization: information activism and retail investor behavior. Journal of Information Technology, 33(1), 31-49. https://doi.org/10.1057/s41265-016-0026-2

Saengchote, K. (2017). The low-risk anomaly: evidence from the Thai stock market. Asian Academy of Management Journal of Accounting and Finance, 13(1), 143-158. https://doi.org/10.21315/aamjaf2017.13.1.6

Shen, L. (2006). Empirical research on the relationship among portfolio size, risk and return of Shanghai securities market. Journal of University of Electronic Science and Technology of China, 6, 1-5.

Shi, Y., \& Cheng, Y. (2006). Empirical study on risk and return of small and medium sized enterprises stock. Shandong Metallurgy, 28(1), 58-60.

Song, Z., Yang, J. \& Li, C. (2004). Empirical study on the risk and return of securities market. China Soft Science, 3, 46-50.

Theodossiou, P., \& Savva, CS. (2016). Skewness and the relation between risk and return. Management Science, 62(6), 1598-1609. https://doi.org/10.1287/mnsc.2015.2201

Wang, P. (2011). Study on the relationship between risk premium and volatility in stock market based on SV-M model. Business Review, 23(6), 54-60.

Wei, T. (2001). Further empirical study of risk measurement and portfolio structure. Nankai Economic Studies, 2, 3-6.

Wei, Y. (2009). Research on capital asset pricing model. Journal of Gansu Lianhe University (Natural Science Edition), 23(1), 37-41.

$\mathrm{Wu}, \mathrm{Ch}$., Zhao, J., \& Wu, G. (2002). Income risk relationship and inertia analysis of China stock market. Journal of Mathematics in Practice and Theory, 32(4), 576-582. 
Yadav, P. L., Han, S. H., \& Rho, J. J. (2016). Impact of environmental performance on firm value for sustainable investment: evidence from large US firms. Business Strategy and the Environment, 25(6), 402-420. https://doi.org/10.1002/bse.1883

Yang, S. (2007). Mean variance model based on MATLAB and EXCEL. Yinshan Academic Journal, 21(2), 42-45.

Yusaku, N., \& Sun, B. X. (2016). Intraday volatility and volume in Chinese stock index cash and futures markets: evidence from high frequency data. Journal of Industrial Engineering and Engineering Management, 30(2), 167-189.

Zhang, S. \& Ma, G. (2000). Stock market risk, return and market efficiency: ARMA-ARCH-M model. The Journal of World Economy, 5, 19-28

Zhao, W. \& Wang, R. (2010). A new method to study the relationship between stock market risk and income: a combined construction method based on Monte Carlo simulation sampling. Productivity Research, 6, 27-29.

Zhao, S., Yuan, D., \& Ren, P. (2018). Volatility spill over effects between our country's index futures and spot market - based on HAR-CAW model. Operations Research \& Management Science, 7(1),153159.

Zhou, X., \& Chen, Y. (2008). The volatility relationship between Shanghai and Shenzhen stock markets. Research on Economics and Management, 8, 77-82.

Zhou, B., Hou, D., \& Shao, Z. (2017). Research on the spillover effects between Chinese stock index futures market and stock market. Economic Review, 8, 37-49.

Zaremba, A. (2016). Is there a low-risk anomaly across countries? Eurasian Economic Review, 6(1), 45-65. https://doi.org/10.1007/s40822-015-0036-3 